\title{
Science and Ethics*
}

\author{
By Dr. Edwin Grant Conklin, Princeton University, Princeton, N.J.
}

$I^{\mathrm{N}}$ $\mathrm{N}$ the early years of the Association, a favourite theme in the annual address of the retiring president was the relation between science and religion. To a majority of modern scientists nothing is more dull and fruitless than attempts to make science the handmaid of theology. But there is an aspect of religion with which science is vitally concerned, namely, ethics, and this has been well called "the religion of science".

Science, as we all know, is tested, verifiable, organized knowledge; ethics pertains to ideals, conduct and character. Any programme looking to human welfare and betterment must include both science and ethics, and there would be a great gain for the world if organized religion and organized science would co-operate more effectively in the promotion of practical ethics.

The differences between the ethics of religion and that of science relate largely to questions of origin rather than of content or purpose. One regards the basis of ethics as supernatural, the other as natural; one derives ethical codes from divine commands, the other from human nature and social utility ; one from direct revelation of the divine will, the other from germ-plasm, endocrines and social instincts. But in spite of these differences in origin, the content is essentially the same. Whether written on tables of stone or on the tables of our hearts, the 'cardinal virtues' are still virtues and the 'deadly sins' are still sins. The deepest instincts of human nature cry out for justice, truth, beauty, sympathy. Ethics that is based on the satisfaction of these desires and needs, on the enduring pleasures of the mind, the rsthetic sense, the love and service of one's fellow men, is not different from the ethics of the divine command to "lay up for yourselves treasures in heaven". Ethics which cultivates justice, truth, courage, beauty, sympathy, love is essentially the same in kind as the two great commandments, "Thou shalt love the Lord thy God with all thy heart, and thy neighbour as thyself'". The new ethics of science does not differ in content from the old ethics of religion, and the commandments of a God within are no less binding than those of \& God without.

Among the generalizations of science which have been charged with the weakening of ethics, first place must be given to the theory of the natural

- Address of the retiring president of the American Association for the Advancement of Science, delivered at Indianapolis on December 28, 1937. evolution of man and of ethical systems. It is a fundamental postulate of modern science that man is a part of Nature, and that his body, mind and social relations have undergone evolution in the long history of the human species. This is not a mere hypothesis but an established fact. There is positive evidence that in long past times there were types of human and partly human beings that were much more brutish in body, mind and social relations than the general average of the present race. There is abundant evidence that ethics has undergone evolution no less than intelligence; it has developed from its beginnings in the primitive family group, to tribal, racial, national and international relations; from the ideals and practices of savagery to those of barbarism and civilization; from the iron rule of vengeance, "an eye for an eye, a tooth for a tooth", to the ideals of love and forgiveness and that highest conception of ethics embodied in the Golden Rule. But as in physical evolution there are retarded individuals and races, so also in the development of ethical ideals some people are far behind others, and all fall short of their highest ideals.

The fact that ethical codes have differed widely among different peoples and in different stages of culture has sometimes been held to prove that there are no general ethical standards, but that ethical actions are merely those which seem good for me or my class or nation. But the fact that there are narrow and selfish codes of ethics as well as broad and generous ones does not prove that all are of equal value and that there are here no standards of excellence. In the living world there are many grades of organization from amoeba to man, many stages of progress from the egg to the adult, many advances in culture from savagery to civilization, but this does not prove that all these stages are of equal human worth; and the fact that truth, beauty and virtue are relative and not absolute does not mean that ignorance and wisdom are equally good.

As is well known, the distinctive principle running through the whole of Darwin's philosophy of evolution is what he called natural selection. Having studied the notable effects of human selection in the production of new breeds of domestic animals and cultivated plants, he sought for some comparable process operating in Nature without human guidance. This he found in the 
Malthusian principle of over-production of populations, the elimination of the less fit and the preservation of favoured races in the struggle for life. Although he regarded environment, whether organic or inorganic, as being in general the principal eliminator of the unfit, he assigned a certain role to the organism itself as selector and eliminator, especially in sexual selection, while in mental, moral and social evolution this autoselection played even a larger part in his philosophy.

It has been charged by many humanists that this Darwinism is destructive of the highest ethical ideals. It is said to be the apotheosis of cruelty and selfishness, to recognize no values except survival, no ideals except success. In this struggle for existence, the weak go under, the strong survive. Militarists and dictators have seized upon this principle as justification of their philosophy that might makes right. Conflicts and wars are said to be both the means and measure of progress, and military training to be the highest type of discipline.

This is, however, a fundamental misconception of natural selection. Darwin himself repudiated this extension of his principle to the struggle between races and nations of men. Those who attempt to extend it into the field of intellectual, social and moral qualities should remember that the standards of fitness are wholly different in these fields. Physically, the fittest is the most viable and most capable of leaving offspring; intellectually, the fittest is the most rational; socially, the fittest is the most ethical. To attempt to measure intellectual or social fitness by standards of physical fitness is hopelessly to confuse the whole question, for human evolution has progressed in these three distinct paths. Man owes his unique position in Nature to this three-fold evolution, and although the factors of physical, intellectual and social progress are always balanced one against another, they are not mutually exclusive.

This leads to the inquiry whether human, or so-called artificial, selection is not also natural. If we define 'natural' as that which is regular and lawful, and not arbitrary and lawless, then human selection is also natural. The study of the behaviour of lower organisms, as well as that of human beings in all stages of development from the infant to the adult, has shown that selection is everywhere taking place. One-celled plants and animals, for example, avoid extremes of heat or cold, move or grow toward certain chemical substances and away from others, take in as food certain substances and reject others. Even germ cells show some of these same properties, and in general it may be said that all living things manifest differential sensitivity and reactivity, and that by a process of trial and error and finally trial and success they generally manage to eliminate reactions that are not satisfactory and to persist in those that are. This is the Darwinian principle extended to the reactions of organisms in which the organism itself is eliminator and selector.

Intelligence in animals and man is arrived at in this same way, by many trials and failures and finally trial and success, remembering of past failures and successes, elimination of the former and persistence in the latter. A cat that by trial and error has learned to open the door of a cage, or a horse that has learned in the same way to lift a latch and open a gate, is intelligent with respect to that one situation; intelligence in human beings is acquired in the same way. Indeed, intelligence is the capacity of profiting by experience, while the ability to generalize experiences is what we call abstract thought, or reasoning.

In his famous Romanes Address in 1892 on "Evolution and Ethics", Prof. T. H. Huxley maintained that ethics consists in opposing the cosmic process of natural selection by intelligent human selection, and in replacing the ruthless destruction of the weak and helpless with human sympathy and co-operation. He illustrated the superiority of human selection by pointing out the fact that a cultivated garden left to Nature grows up to weeds and, therefore, that human intelligence can improve on the blind processes of Nature in meeting human needs.

All this is undoubtedly true ; we are continually improving on Nature for our own purposes; all agriculture, industry, medicine, education are improvements on Nature. The notion that Nature is always perfect is certainly false, and the cry, "Back to Nature", is more likely to be a call to regress than to progress. But it is a mistake to suppose that human intelligence and purpose, social sympathy, co-operation and ethics in general are not also parts of Nature and products of natural evolution. In Darwin's theory the environment eliminates the unfit individual, but in individual adaptations to new conditions the organism itself eliminates many useless or injurious responses. In such cases the organism rather than the environment is the eliminator or selector, either by the hit or miss process of 'trial and error', or by the vastly more rapid and less wasteful method of remembered experience, that is, by intelligence. Thus intelligence can improve on the blind processes of Nature, because it is not blind, although it also is natural ; and thus intelligence has become a prime factor in evolution.

It is clear that social ethics assumes the ability and the responsibility of individuals to regulate behaviour in accordance with ideals and codes of conduct. It therefore demands freedom to choose between alternatives that are offered. Without 
such freedom there can be no responsibility, no duty, no ethics. It has long been the creed of certain rigidly mechanistic scientists that freedom, responsibility and duty are mere delusions, and that human beings are automata, thinking, feeling and doing only those things which were predetermined by their heredity and environment over which they have no control. This fatalistic creed was in large part a deduction from the determinism of Nature which was revealed in mathematics, astronomy, physics and chemistry, and was then extended by certain physiologists to all vital phenomena, including human life and personality. Indead, some of these 'hard determinists' went so far as to maintain that the whole course of human history was predetermined in the original constitution of the universe, that nations had risen and fallen, cultures and civilizations had come and gone, and that the present state of the world and its future destiny were all determined by inexorable laws. However, many biologists who investigated the behaviour of animals refused to regard them as mere automata, and students of human behaviour generally held that there must be some flaw or break in this logical chain that bound man helpless on the wheel of fate, some fallacy in the logic that denied him all freedom and responsibility, some monstrous error in the conclusion that saints and sinners, philanthropists and fiends were mere pawns or puppets in a game in which they were moved by forces over which they had no control.

The 'closed universe' of physical science is strangely unlike the world of human experience, but its adherents argue that experience is subject to delusions from which rigid logic and genuine science are supposed to be exempt. In such a 'closed universe' man does only what he is compelled to do ; there is no freedom, responsibility or duty, no place for purposive education, ethics or religion.

As a way of escape, mathematicians and physicists, who were most impressed by the determinism of inanimate Nature, were generally inclined to adopt some form of Cartesian dualism, which would endow living beings, and especially man, with an unmaterial principle or soul which was not subject to this rigid determinism. But, on the other hand, students of life phenomena in general could find no sufficient evidence for such dualism, and hence arose the strange anomaly of physiologists and psychologists becoming more rigid determinists, so far as life and man are concerned, than students of the physical sciences.

Several scientists have expressed the view that Heisenberg's principle of indeterminacy in the subatomic field can somehow be converted into the novelty, creativity and freedom manifested by living things. But no one has shown explicitly how this can be done. Furthermore, biologists generally do not admit any fundamental indeterminacy in the behaviour of living beings. Novelty, creativity and freedom, wherever their origin has been traced, are found to be caused by new combinations of old elements or processes, whether these be atoms, molecules, genes, chromosomes, cells, organs, functions, or even sensations, memories and ideas. By such new combinations of old elements there emerge all the new properties of chemical compounds, and by new combinations of genes and chromosomes and environmental stimuli all the novelties of heredity and development arise. There is good evidence that even psychical properties, such as consciousness, intelligence and will, emerge in the process of development because of specific combinations of physical and psychical factors. This is, indeed, the whole philosophy of evolution; namely, that the entire universe, including man and all his faculties and activities, are the results of transformation rather than of new-formation, of emergence rather than of creation de novo.

Freedom does not mean uncaused activity; "the will is not a little deity encapsuled in the brain", but instead it is the sum of all those physical and psychical processes, including especially reflexes, conditionings and remembered experiences, which act as stimuli in initiating or directing behaviour. The will is not undetermined, uncaused, absolutely free, but is the result of the organization and experience of the organism, and in turn is a factor in determining behaviour. Therefore, we do not need to import from subatomic physics the uncertain principle of uncertainty in order to explain free will. The fact that man can control to a certain extent his own acts as well as phenomena outside himself requires neither a little dæmon in the electron nor a big one in the man.

Just one hundred years ago Wordsworth wrote :

"Man now presides

In power where once he trembled in his weakness; Science advances with gigantic strides,

But are we aught enriched in love and meekness?"

(Miscellaneous Sonnets, Part 3, 41, Jan. 1838.)

These lines are much more significant to-day than when they were penned, for so far as our knowledge of and control over natural forces and processes are concerned, we live in a new world.

"But are we aught enriched in love and meekness ?"

Neither in human nature nor in social relations has progress kept pace with science. This is not the fault of science but rather of man and of society. The great advances in the applications of science have often been used for selfish purposes 
rather than for social welfare. Scientific progress in medicine and sanitation is far in advance of its social utilization, but not in advance of its urgent need. Rational and peaceful means of solving class conflicts and of preventing wars would be vastly less costly and more effective than strikes and armaments. The fact is that social progress has moved so much slower than science that one might say that scientific progress is matched against social stagnation. Many thoughtful persons are asking: "Will science, which has so largely made our modern civilization, end in destroying it ?"

A fundamental fact is that improvements in human nature are not keeping pace with increasing knowledge of and control over outer Nature. By means of language, writing, printing, the radio, and all the means of communication and conservation of knowledge, each human generation transmits its accomplishments to succeeding ones.

Thus present science, culture and civilization represent the accumulated experience and knowledge of all the past, each succeeding generation standing, as it were, on the shoulders of preceding ones. Every individual, on the other hand, begins life where all his ancestors began, namely, in the valley of the germ cells; he then climbs to the summit of maturity and goes down into the valley of death. But society, gifted with continuous life, passes on with giant strides from mountain top to mountain top; and so it happens that science and civilization in general outrun individual heredity, for the learning and acquirements of each generation are not transmitted to succeeding ones through the germ cells but only through social contacts. For this reason increasing knowledge and power have greatly outrun improvements in inherent human nature.

What is the remedy, if any, for the lag in the progress of human nature behind the progress of science and society? Eugenics has been proposed as a possible and necessary solution of this problem. Undoubtedly great improvement in human heredity could be effected if the principles of good breeding which are used with such notable results in the improvement of domesticated animals and cultivated plants were to be used in the breeding of men. There is no doubt among students of heredity that by means of a system of selective breeding a healthier, longer-lived, more intelligent, more emotionally stable human type could be developed. But the difficulties in the way of such a eugenical programme are enormous where the human stock is so mixed, as it is in almost all races of men, and where the rules of good breeding would have to be self-administered or imposed by authorities that are influenced by social, racial or ethical prejudices. Even if these obstacles could be overcome and this programme wisely and persistently followed, it would take thousands of years to bring about any marked improvement in the masses of mankind.

Fortunately there are other and more rapidly acting remedies for this disharmony between social progress and biological inheritance. Heredity determines only the capacities and potentialities of an organism; the realization of those potentialities depends upon development, which is greatly influenced by environment, hormones, health or disease, use or disuse, conditioned reflexes or habits. In every individual there are many capacities that remain undeveloped because of lack of suitable stimuli to call them forth. Since these inherited potentialities may be social or antisocial, good or bad, it is the aim of enlightened society to develop the former and to suppress the latter. In the heredity of every human being there are many possible personalities; which one of these becomes actual depends upon developmental stimuli. Each of us might have been much better or much worse than we are if the conditions of our development had been different. Endocrinologists and students of nutrition are already preventing or overcoming many of the deficiencies or defects that arise in the course of development. In these respects science is contributing greatly to human welfare and to practical ethics.

But of all the possible means of rapidly improving social conditions, ethical education is probably the most promising. Indeed, education, based on a knowledge of the principles of development and aimed at the cultivation of better relations among all classes, races and nations, is the chief hope of social progress.

The most enduring effect of education is habit formation. Good education consists in large part in the formation of good habits of body, mind and morals. Heredity is original or first nature ; habits are second nature, and for character formation and social value they are almost as important as heredity itself. To trust entirely to heredity to improve men or society is to forget that heredity furnishes capacities for evil as well as for good, and to disregard the universal experience of mankind that human nature may be improved by humane nurture.

On these grounds certain humanists have proposed that art, literature, history and political and moral philosophy should replace science in the educational programme, since, as they assert, science, being materialistic, non-ethical and lacking in high ideals, neglects or destroys the real values of life. The president of the University of Chicago has recently called science a failure in the educational process, and he urges a return to philosophy as the only sure road to sound discipline and true culture. Those who have never experienced the 
discipline and ennobling effects of scientific studies fear that science will destroy our civilization, and are calling upon educators to repent and to return to the good old subjects of classical learning. Without discussing the subject in general, it may be remarked that it was not science that caused the decay of former civilizations, nor was it in the power of classic art, literature and philosophy to save those civilizations. Certainly there are no other studies than science that distinguish so sharply truth from error, evidence from opinion, reason from emotion; none that teach a greater reverence for truth or inspire more laborious and persistent search for it. Great is philosophy, for it is an attempt at a synthesis of all knowledge, but if it is true philosophy it must be built upon science, which is tested knowledge.

"To the solid ground of nature

Trusts the Mind that builds for aye."

Education, then, which looks to the highest development of the physical, intellectual and moral capacities of men is the chief hope of human progress. Even any possible programme of improvement of inherited human nature must rest upon education concerning the principles of heredity and the methods of applying them to the breeding of men. Without waiting for the slow improvement of human nature through eugenics, great progress can be made toward the 'good society' by the better development of the capacities we already possess. As a matter of fact, all of the great advances from savagery to the highest civilizations have been made without corresponding improvements in heredity.

Although our inherited capacities have not greatly increased since our progenitors rose out of barbarism, yet there has grown up within us an increasing respect for the human mind and a deep conviction of the importance of its freedom. We who are the inheritors of the tradition of liberty of thought, speech and press, and who believe that freedom and responsibility are essential to all progress, should use our utmost influence to see that intellectual freedom shall not perish from the earth. Such freedom has been essential for the advance of science, and the time has come when science should stand for freedom, especially in those countries where force, war and unutterable ferocity are used to compel acceptance of political, social or scientific creeds.

There is no possibility that all men can be made alike in personality, nor any reason why all races and nations should hold the same political and social ideals. But there are good grounds for hoping that they may come to cherish the same fundamental ethical concepts; for the needs and satisfactions, the instincts and emotions of all men are essentially similar. Science is everywhere the same in aims and methods, and this fact greatly strengthens the hope that in a world bound together by science into one neighbourhood there may come to be common ideals regarding fundamental ethics. The greatest problems that confront the human race are how to promote social cooperation; how to increase loyalty to truth, how to promote justice, brotherhood ; how to expand ethics until it shall embrace all mankind. This is a problem for science as well as for government, education and religion. Each of these agencies has its own proper functions to perform.

The ethics of science regards the search for truth as one of the highest duties of man; it regards noble human character as the finest product of evolution; it considers the service of all mankind as the universal good; it teaches that both human nature and humane nurture may be improved, that reason may overcome unreason, co-operation supplement competition, and the progress of the human race through future ages be promoted by human intelligence and purpose.

In its practical aspects the ethics of science includes everything that concerns human welfare and social relations; it includes eugenics and all possible means of improving human heredity through the discovery and application of the principles of genetics; it is concerned with the best means of attaining and maintaining an optimum population; it includes all those agencies, such as experimental biology and medicine, endocrinology, nutrition and child study, which promise to improve bodies and minds. It includes the many scientific aspects of economics, politics and government; it is concerned especially with education of a kind that establishes habits of rational thinking, generous feeling and courageous doing.

In spite of notable advances of our knowledge of these subjects, we still know too little about human nature and the causes of social disorders. The extension of the methods of experimental science into their study is bound to be one of the major advances of the future, as it has in the field of medicine since the days when human ills were thought to be due to demons. The ills of society have natural causes and they can be cured similarly by controlling those causes.

It has always been true and will continue to be true that knowledge outruns practice and that ideals are better than performance. How can men be induced to live up to the best they know? How can they be brought to substitute the spirit of service for selfishness, love for hate, reason for unreason? The long efforts of past centuries show that there is no rapid solution of this great problem. But in the co-operation of science, education and religion there is hope for the future. 